\title{
Comunicación
}

\section{SEROPREVALENCIA DE Brucella sp. EN BOVINOS DEL DISTRITO DE TARMA, JUNÍN}

\author{
Seroprevalence of Brucella SP. in Cattle of Tarma District, Junín-Peru \\ Sandra Ventocilla G. ${ }^{1}$, Alfredo Delgado C. ${ }^{1.2}$, Hermelinda Rivera G. ${ }^{3}$ y \\ Roberto Evaristo R. ${ }^{1,4}$
}

\section{RESUMIEN}

El objetivo del presente estudio fue determinar la presencia de Brucella sp. en bovinos del distrito de Tarma-Junín, mediante la detección de anticuerpos en suero a través de la prueba de Rosa de Bengala. Se procesaron 344 muestras de suero y no se encontraron animales serorreactores a Brucella sp., lo cual sugiere la ausencia de la bacteria o una prevalencia menor al $1 \%$ en la población estudiada. Estos resultados demandan un plan estricto de vigilancia epidemiológica y la implementación de un programa de control y erradicación de brucelosis bovina en el distrito de Tarma con el fin de mantener al área "libre" de la enfermedad.

Palabras clave: brucelosis bovina, Brucella sp., seroprevalencia, Rosa de Bengala, anticuerpos

\section{AbSTRACT}

The objective of this study was to determine the presence of Brucella sp. in cattle of the district of Tarma, Junin-Peru. Blood samples of 344 cows were collected for detection of antibodies against Brucella sp. by Rose Bengal Plate test. None of the samples tested resulted positive to antibodies against Brucella sp. The results suggest the absence of the bacteria or that the prevalence is less than $1 \%$ in the evaluated population. The results might be used for the Peruvian National Service of Animal Health to establish an epidemiological surveillance programme for maintaining the area "free" of the disease.

Key words: bovine brucellosis, Brucella sp., seroprevalence, Rose Bengal, antibodies

\footnotetext{
${ }^{1}$ Clínica de Animales Mayores, ${ }^{3}$ Laboratorio de Microbiología y Parasitología Veterinaria, Facultad de Medicina Veterinaria, Universidad Nacional Mayor de San Marcos, Lima

${ }^{2}$ E-mail: aldelgadoc@gmail.com

${ }^{4}$ Dirección actual: Facultad de Veterinaria y Zootecnia, Universidad Peruana Cayetano Heredia, Lima
} 
La brucelosis bovina es una enfermedad infecciosa y de distribución mundial, de gran impacto en la salud pública y en la producción pecuaria, afectando la economía de los países donde aun no se ha podido erradicar (Aréstegui et al., 2001). Las estimaciones oficiales sobre las pérdidas anuales por brucelosis bovina en América Latina son de US\$ 600 millones, originadas por la disminución de la producción de carne, leche y de los valores de venta de los animales infectados (Gil y Samartino, 2000).

Hace algunos años se reconocían seis especies de Brucella (B. melitensis, $B$. abortus, B. suis, B. neotomae, B. ovis y $B$. canis). Sin embargo, se ha demostrado una homología genética superior al $95 \%$ entre las especies, la cual ha llevado a agruparlas desde el punto de vista taxonómico, dentro de una única especie: $B$. melitensis (Orduña et al., 2002). Recientemente, se ha aislado la $B$. maris en mamíferos marinos. El patógeno principal en el ganado bovino es la $B$. abortus; sin embargo, pueden infectarse por $B$. suis y B. melitensis cuando las vacas comparten el pastoreo o las instalaciones con cerdos, cabras u ovejas infectados (Blasco, 2002).

La forma principal de contagio es por vía digestiva, que se produce cuando los animales lamen descargas vaginales, membranas fetales, fetos abortados, terneros recién nacidos y genitales de otros animales, y que están contaminados con Brucella. Otras vías menos frecuentes son la genital, respiratoria, percutánea, conjuntival e intramamaria (Samartino, 2003). La diseminación septicémica de $B$. abortus es ayudada por la circulación de macrófagos, permitiendo así la colonización del tejido reticuloendotelial y órganos genitales principalmente (William, 1999).

La especial afinidad que estas bacterias tienen por el endometrio grávido y por la placenta fetal condiciona que la principal manifestación clínica de la infección sea el aborto durante el último tercio de la gesta- ción (Blasco, 2002). El eritritol, un hidrato de carbono producido por el feto y capaz de estimular el crecimiento y multiplicación de $B$. abortus, se encuentra en concentraciones más elevadas en los líquidos placentarios y fetales, y es el responsable de la localización de la infección en estos tejidos, lo que explicaría la gran susceptibilidad de los tejidos fetales del bovino (Acha y Szyfres, 2003).

La información epidemiológica sobre brucelosis suele ser deficiente, pues frecuentemente está presente sin ser notificada adecuadamente o bien existen sesgos propiciados por los estudios de diagnóstico (GarcíaCarrillo y Lucero, 1993). En el Perú, el Servicio Nacional de Sanidad Agraria (SENASA) viene realizando un programa sanitario de control y erradicación de brucelosis bovina basado en métodos serológicos convencionales tales como la Aglutinación en placa, Rosa de Bengala, Anillo en Leche; pruebas confirmatorias como Fijación de Complemento y ELISA; y el sacrificio de animales serorreactores (SENASA, 2003).

Los datos sobre la prevalencia de brucelosis en el área andina son escasos, habiéndose reportado en el Valle del Mantaro una prevalencia de $0.28 \%$ (Cruz, 1996). Asimismo, los últimos reportes realizados por el SENASA en el año 2003 denotan una nula prevalencia en el departamento de Junín, aunque no se precisa que dentro de este número de animales se encuentren los del distrito de Tarma. Es así que el presente trabajo tuvo por objetivo determinar la presencia de la brucelosis bovina en las diversas comunidades del distrito de Tarma.

El distrito de Tarma tiene una extensión territorial de $459.95 \mathrm{~km}^{2}$ (INEI, 2004) y comprende 40 comunidades campesinas con sus respectivos poblados. E1 territorio presenta altitudes entre los 3450 a $4462 \mathrm{msnm}$, con una temperatura promedio anual entre los 5 y $12{ }^{\circ} \mathrm{C}$ y con una precipitación pluvial promedio de 300 hasta $800 \mathrm{~mm} /$ año (Municipalidad de Tarma, 2004). La población bovina 
Cuadro 1. Distribución de la población bovina de Tarma, Junín, según sectores y número de muestras, para determinar la seroprevalencia de Brucella sp. (2004)

\begin{tabular}{lccc}
\hline \multirow{2}{*}{ Sectores } & Población bovina & \multicolumn{2}{c}{ Muestras } \\
\cline { 3 - 4 } & & Estimadas & Trabajadas \\
\hline Este & 341 & 73 & 86 \\
Oeste & 337 & 73 & 74 \\
Norte & 320 & 69 & 76 \\
Sur & 386 & 298 & 344 \\
\hline
\end{tabular}

Fuente: Vacunación anti-aftosa bovina I fase (SENASA, 2001)

del distrito de Tarma es de 1384 cabezas de ganado bovino, obtenida por los datos de la campaña de vacunación Anti-Aftosa bovina I Fase (SENASA, 2001). El tipo de ganado, en su mayoría, es criollo y criado bajo un sistema de producción extensiva con pastura natural principalmente. Los animales muestreados fueron bovinos en edad reproductiva a partir de los 24 meses (edad promedio de madurez sexual en dicho distrito). El ganado bovino de la zona solo se vacuna, como norma, contra el carbunco sintomático (INEI, 2004).

Para el presente estudio se utilizó el muestreo aleatorio por sectores de crianza. Se estableció el tamaño muestral mediante el método de prevalencia límite del $1 \%$ con un nivel de confianza del 95\%, dando como resultado 298 animales. Para mejorar la cobertura del distrito, la muestra fue estratificada en forma proporcional en base a los sectores este, oeste, norte y sur. Al final, se llegó a obtener 344 muestras de suero (Cuadro 1).

Las muestras de sangre se obtuvieron entre agosto y octubre de 2004 por venopunción de la vena coccígea, vena yugular o vena mamaria. El suero fue separado del coágulo; y dentro de las 24 horas de tomada la muestra, fue trasvasado en viales de $5 \mathrm{ml}$ y conservado a temperatura de congelación $\left(-20^{\circ} \mathrm{C}\right)$ para su posterior procesamiento.
La presencia de Brucella sp. se determinó mediante la prueba de Rosa de Bengala, internacionalmente estandarizada para el diagnóstico serológico de la brucelosis bovina, y recomendada por el Comité Mixto FAO/OMS de expertos en brucelosis y por la OIE. Es una prueba cualitativa muy sensible, económica, rápida y de fácil ejecución que se puede emplear como prueba de detección inicial (Radostits et al., 2002). Adicionalmente, se realizó la prueba confirmatoria de Fijación del Complemento a aquellos sueros que provenían de animales con antecedentes de aborto. Las pruebas se realizaron en Tarma, y las contramuestras se hicieron en el Laboratorio de Microbiología del SENASA, Lima.

Los 344 sueros resultaron negativos a las dos pruebas de laboratorio por lo que no se determinaron anticuerpos contra Brucella sp. Este resultado es indicativo que los animales no tuvieron experiencia con la Brucella abortus, B. melitensis o B. suis, y concuerda con los resultados previos obtenidos en el Valle del Mantaro (Jauja, Concepción y Huancayo), donde se encontró una prevalencia menor a $1 \%$ con las pruebas de Rosa de Bengala y Aglutinación en placa y de $0.28 \%$ con la prueba de ELISA indirecta (Cruz, 1996). 
El distrito de Tarma es el centro de una red de comercialización ganadera regional entre costa (Lima), sierra (Tarma, Oroya, Huancayo y Cerro de Pasco) y selva (La Merced, Satipo, Oxapampa y Villa Rica). Esta condición, sumada a las ferias en donde se venden animales, constituyen medios favorables para la difusión de enfermedades como la brucelosis. Sin embargo, la ausencia de reactores a Brucella sp. en los animales muestreados podría deberse a que esta enfermedad no ha ingresado al distrito. La información existente permite considerar al distrito de Tarma como zona libre de brucelosis bovina; sin embargo, esta condición podría verse amenazada si no se controla el tránsito de animales a la ciudad de Tarma. Además, le correspondería un programa de erradicación mediante pruebas serológicas de diagnóstico y el sacrificio de los animales que resultaran positivos hasta erradicar completamente los posibles animales reactores (Acha y Szyfres, 2003).

Por otro lado, las encuestas realizadas a los propietarios de los animales, revelaron antecedentes de problemas reproductivos (abortos) en cuatro vacas muestreadas, signo clínico más importante de la brucelosis. No obstante, los supuestos abortos pudieron deberse a otros agentes patógenos (BVD, Neospora caninum, Leptospira hardjo) o a periodos de anestro por mal manejo de la cría al pie. Asimismo, se evidenció un gran desconocimiento de la brucelosis bovina en esta zona, por lo cual se requerirá educación sanitaria para que el programa de control y erradicación sea eficiente.

La mayoría de los estudios de prevalencia de brucelosis bovina realizados en el país se han llevado a cabo en hatos lecheros, muchos de los cuales comercializan la leche hacia las ciudades más cercanas $\mathrm{y}$, mayormente, se encuentran bajo una crianza intensiva. Esta realidad puede representar un peligro y amenaza para la salud animal y pública, sobre todo por las zonas en donde la leche se destina al autoconsumo y en donde predominan los animales criados al pastoreo como es el caso del distrito de Tarma.

\section{Literatura Citada}

1. Acha P, Szyfres B. 2003. Zoonosis y enfermedades transmisibles comunes al hombre y los animales. $3^{\text {ra }}$ ed. Vol 1. Washington, USA: Organización Panamericana de la Salud. Pub. Científica y Técnica N. ${ }^{\circ} 580$.

2. Aréstegui M; Gualtieri C, Domínguez J, Scharovsky G. 2001. El género Brucella y su interacción con el sistema mononuclear fagocítico. Vet Mex 32(2): 131-139.

3. Blasco J. 2002. Brucelosis animal: la enfermedad y medidas para su control y erradicación. En: Manual de brucelosis. España: Junta de Castilla y León. p 31-43.

4. Cruz J. 1996. Prevalencia de la brucelosis bovina en la cuenca lechera del valle del Mantaro. Tesis Médico Veterinario. Lima: Facultad de Medicina Veterinaria, Univ. Nacional Mayor de San Marcos. 28 p.

5. García-Carrillo C, Lucero N. 1993. Diagnóstico bacteriológico. En: De Diego AE, eds. Brucelosis bovina. Buenos Aires, Argentina: Hemisferio Sur. p 97-98.

6. Gil A, Samartino L. 2000. Brucelosis. En: Zoonosis en los sistemas de producción animal de las áreas urbanas y periurbanas de América Latina. Livestock Policy Discussion Paper N. ${ }^{\circ}$ 2. Food and Agriculture Organization. $p$ 23-29.

7. [INEI] Instituto Nacional de Estadística e Informática. 2004. Censo Nacional Agropecuario de 1994. [Internet], [28 diciembre 2004]. Disponible en: http:/ /www.inei.gob.pe/

8. Municipalidad de Tarma. 2004. Aspectos generales de la provincia de Tarma. [Internet], [28 diciembre 2004]. Disponible en: http://www. munitarma.gob.pe/Distritos/Tarma.htm 
9. Orduña A, Bratos M, Abad R, Ruiz L, De Frutos M, Rodríguez A. 2002. La brucelosis. Etiología y origen de la infección humana. En: Manual de brucelosis. Zamora, España: Junta de Castilla y León. p 13-20.

10. Radostits O, Gay C, Blood D, Hinchcliff K. 2002. Medicina veterinaria. Tratado de las enfermedades del ganado bovino, ovino, porcino, caprino y equino. $9^{\mathrm{a}}$ ed. Vol I. Madrid, España: Ed. McGraw-Hill Interamericana. 1920 p.

11. Samartino L. 2003. Conceptos generales sobre brucelosis bovina. Jornada de Actualización sobre Brucelosis Bovina.
Argentina: Instituto Nacional de Tecnología Agropecuaria (INTA). $7 \mathrm{p}$.

12. [SENASA] Servicio Nacional de Sanidad Agraria. 2001. Vacunación antiaftosa bovina I Fase. Lima: SENASA. $14 \mathrm{p}$.

13. [SENASA] Servicio Nacional de Sanidad Agraria. 2003. Programa de control y erradicación de tuberculosis y brucelosis bovina. Lima, Perú. [Internet], [26 diciembre 2004]. Disponible en: http:/ /www.senasa.gob.pe

14. William C. 1999. Enfermedades del ganado vacuno lechero. Zaragoza, España: Ed. Acribia. 678 p. 